\title{
Using the ROTAN model to predict nitrogen loads to Lake Rotorua, New Zealand
}

\author{
$\underline{\text { C.C. Palliser }}^{\text {a }}$, A. Parshotam ${ }^{a}$ and J.C. Rutherford ${ }^{a}$ \\ ${ }^{a}$ NIWA, PO Box 11-115, Hamilton, 3251, New Zealand \\ Email: c.palliser@niwa.co.nz
}

\begin{abstract}
Nitrogen limits phytoplankton growth in several lakes in the central volcanic plateau, North Island, New Zealand. Since the 1940-1950s the intensification of livestock farming has increased nitrogen exports from pasture and contributed to deterioration in lake water quality. These changes went undetected for many years because much of the nitrate exported from pasture is transported to the lakes via deep aquifers with mean residence times (MRTs) of decades to over a century. However, increasing trends are now apparent in stream nitrogen concentrations, and modelling is being undertaken to help managers decide how best to reduce lake loads.
\end{abstract}

Morgenstern et al. (2005) measured tritium tracer concentrations in springs, wells and groundwater-fed streams in the Lake Rotorua catchment. They used these data along with measured nitrogen loads to the lake, to fit a combined exponential-piston flow model (EPM) to describe the groundwater system of the Lake Rotorua catchment. This fitting involved obtaining the MRTs and the fractions of plug flow and mixed (or exponential) flow in the EPM model for the groundwater emerging in the nine major streams that flow into Lake Rotorua. Assuming an average flow for each of the streams and a constant nitrogen export from the land that started in 1950, Morgenstern and Gordon (2006) used the EPM model to predict the nitrate load to the lake for 2005 and into the future (which included a steady state load).

The ROTAN model (Rutherford et al., 2011) simulates land use, aquifers, springs, streams and total nitrogen input to the lake from 1900-2100 using a daily or weekly time step. Nitrogen exports are estimated using the OVERSEER ${ }^{\circledR}$ model (http://www.overseer.org.nz), combined with historic land use maps and agricultural statistics. It uses the mean residence times estimated by Morgenstern et al. (2005) to size the aquifers. ROTAN has been calibrated using stream and nitrogen concentration data from the nine major streams that flow into Lake Rotorua. Morgenstern et al. (2005) assumed that all of the nitrogen reached the lake via the same aquifer, whereas with ROTAN the best fit to stream flow and nitrogen concentration data was obtained by assuming that the average proportion of nitrogen reaching the lake via the deep groundwater was $53 \%$, and the remaining $47 \%$ reached the lake via shallow groundwater and near-surface flow. ROTAN accounts for historical land use and therefore the nitrogen export from the land varies temporally unlike the exports in the EPM model of Morgenstern which are constant either side of the step change in exports in 1950 or 1965.

This paper explores the effect that differences between the two models have on estimating both the current load, and future loads to the lake when different land use and mitigation measures are modelled. The ROTAN model, for example, found that if the total nitrogen export remains at the current (2010) level, the lake load is likely to increase slowly over the next 60-70 years and to approach a steady state of $724 \mathrm{tN} / \mathrm{yr}$ by about 2080. ROTAN simulations also indicate that if total nitrogen exports were reduced by 320-350 tN/yr in 2015 and held constant, then the lake load is likely to decrease fairly quickly and approach the lake load target of $405 \mathrm{tN} / \mathrm{yr}$ within about 35 years. This response time is faster than expected and this paper describes the use of the Morgenstern model as an independent check on the ROTAN result to see if it obtains a similar response time. The loads predicted by the two models do not match particularly well from 1940-2015 and this gives less confidence in comparing them. However, after 2015 they predict similar loads with the Morgenstern model calculating that it will take about 45 years for the lake load target to be reached. This response time is longer than ROTAN's one of 35 years, but is sufficiently similar to give confidence in ROTAN's result.

Keywords: Nitrogen, models, lake load 


\section{INTRODUCTION}

Lake Rotorua is situated in the central volcanic plateau, North Island, New Zealand (Figure 1) and is important for recreation and tourism. Nitrogen currently limits the phytoplankton growth in the lake although the lake may be moving towards being phosphorus limited. Baseflow nitrate concentrations in major streams draining into Lake Rotorua increased significantly over the period 1968-2003 (Rutherford, 2003) and this trend is believed to have contributed to recent poor lake water quality. Since the 1940-1950s the intensification of livestock farming has increased nitrogen exports from pasture and contributed to the trend. However, the effects of the intensification went undetected for many years because much of the nitrate exported from pasture is transported to the lakes via deep aquifers with mean residence times (MRTs) of decades to over a century. The nitrogen load ${ }^{1}$ to Lake Rotorua is now significantly higher than the target load target of $405^{2} \mathrm{tN} / \mathrm{yr}$ set for the lake (EBoP, 2009).

Strategies for lake restoration include land use change and measures to reduce nitrogen and phosphorus exports from farmland. The regional council (Bay of Plenty Regional Council) requires effective tools for predicting the cumulative effect of land use change and mitigation measures on nutrient inputs to the lakes. Two challenges for managers are:

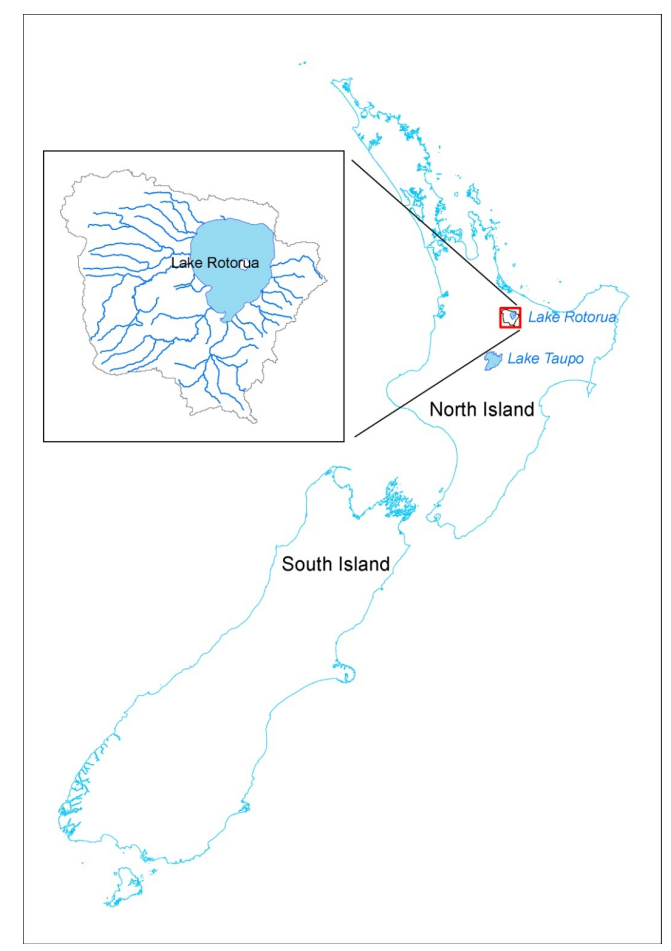

- Determining which properties contribute diffuse nitrogen via runoff to the lake, given that the boundaries of aquifers draining to the lake may not coincide with the boundaries of the surface catchment.

- Predicting how quickly reductions of nutrient export from different parts of the catchment will reduce inputs to the lake, given the groundwater lags in the system.

Morgenstern and Gordon (2006) developed a model to help answer the second challenge by estimating the effects of a step change in land use during the 1940-1950s, including predictions of the nitrogen 'loads to come'. The ROTAN (ROtorua and TAupo Nitrogen) model (Rutherford et al., 2011) complements Morgenstern and Gordon (2006) by simulating temporal and spatial variations in rainfall, infiltration, land use and nitrogen export and refining estimates of the magnitude and timing of the nitrogen 'loads to come'.

Figure 1. Lake Rotorua, New Zealand.

This paper compares predictions by the two models of the time it takes for loads to the lake to decrease following a reduction in nitrogen exports. Rutherford et al. (2011), using the ROTAN model, found that if nitrogen exports were reduced by about $320-350 \mathrm{tN} / \mathrm{yr}$ and held constant, then the lake load is likely to decrease fairly quickly and approach the target of $405 \mathrm{tN} / \mathrm{yr}$ within about 35 years. The actual recovery time is likely to be slower than this because the land use changes and mitigation measures (that result in the nitrogen export reduction) are unlikely to all occur in a single year as assumed, but will occur gradually over several years. Nevertheless the response time of about 35 years is faster than expected and this paper

\footnotetext{
1 'Export' refers to the flux of nitrogen ( $\mathrm{tN} / \mathrm{yr}$ ) that leaves a parcel of land or a point source, and 'load' refers to the flux (tN/yr) that reaches Lake Rotorua after allowing for attenuation (viz., any permanent losses (e.g., denitrification) and temporary storage (e.g., groundwater lags)).

${ }^{2}$ The target given in EBoP (2009) is actually $435 \mathrm{tN} / \mathrm{yr}$ but this figure includes $30 \mathrm{tN} / \mathrm{yr}$ from rainfall which is not considered in the models here.
} 
describes the use of Morgenstern and Gordon's (2006) model as an independent check on the ROTAN result to see if it obtains a similar response time.

\section{MODELS}

\subsection{ROTAN}

ROTAN is a daily/weekly time-step, conceptual rainfall-runoff-groundwater model similar to the HBV-N model (Pettersson et al., 2001; Tamura et al., 1999). The model runs within ArcGIS using Access databases. Details of the model are given in Rutherford et al. (2008, 2009, 2011). It simulates land use, aquifers, springs,

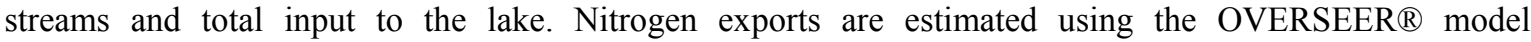
(http://www.overseer.org.nz), and from historic land use maps and agricultural statistics. It uses the MRTs as estimated by Morgenstern et al. (2005) (Figure 2) to size the aquifers. ROTAN has been calibrated using stream and nitrogen concentration data from the nine major streams that flow into Lake Rotorua. Morgenstern et al. (2005) assumed that all of the nitrogen reached the lake via deep groundwater, whereas with ROTAN the best fit to the stream and nitrogen concentration data was obtained by assuming that the average proportion of nitrogen reaching the lake via the groundwater was $53 \%$, and the remaining $47 \%$ reached the lake via near-surface flow and shallow groundwater. ROTAN also accounts for historical land use and the nitrogen exports from the land vary temporally - unlike exports in the Morgenstern model which are held constant after the step change in 1950 or 1965.

In Rutherford et al. (2011) various scenarios were modelled in order to estimate the magnitude and timing of future nitrogen loads to the lake. The scenarios ran from 1900-2100 using a weekly time step. These scenarios included one called 'R-0' and another called 'R-350'. Both scenarios used historical land use until 2010 and from 2010-2015 they used the land use as it was in 2010. From 2015-2100, R-0 continued to use 2010's land use (a 'do-nothing' scenario), whereas R-350 reduced the 2010 nitrogen export of $725 \mathrm{tN} / \mathrm{yr}$ by $350 \mathrm{t}$ in 2015 and kept it reduced by that amount until the end of the simulation (2100). The steady state load (to the lake) as calculated by ROTAN for scenarios R-0 and R-350 equalled 724 and 380 tN/yr respectively, which means that for steady state R-350 reduced the R-0 load by $48 \%$.

\subsection{Morgenstern and Gordon (2006)}

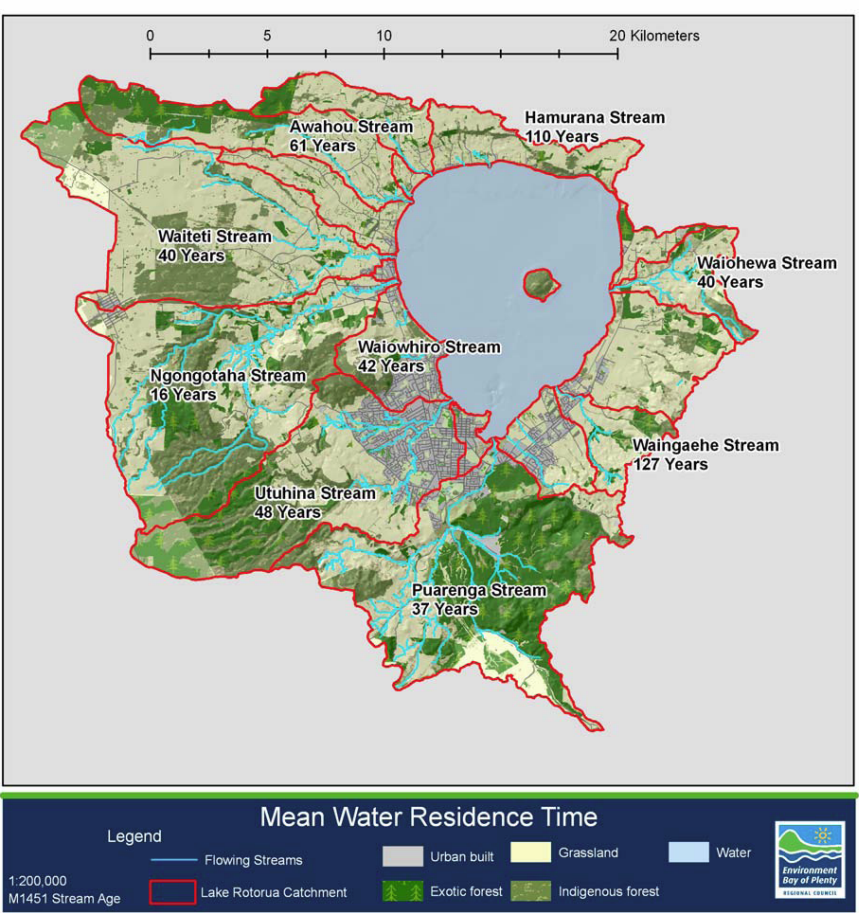

Figure 2. Mean water residence times near the mouth for the nine major streams that flow into Lake Rotorua (taken from Morgenstern and Gordon, 2006).
Morgenstern et al. (2005) measured tritium tracer concentrations in springs, wells and groundwater-fed streams in the Lake Rotorua catchment. Morgenstern and Gordon (2006) used these data, along with measured nitrogen loads to the lake, to fit a combined exponential-piston flow model (EPM) to describe the groundwater system of the Lake Rotorua catchment. This fitting involved obtaining the MRTs and the fractions of mixed (or exponential) flow in the model for the groundwater emerging in the nine major streams that flow into Lake Rotorua (Figure 2). The model assumed a single fully mixed $(100 \%$ exponential flow) aquifer for each catchment in five of the nine catchments, with the remaining four catchments' aquifers being incompletely mixed (viz., there is some piston flow as well). 
Assuming steady flow and a step change in nitrogen export in either 1950 (for seven of the catchments) or 1965 (for the remaining two), Morgenstern and Gordon (2006) used their model to predict the stream nitrate loads to the lake for into the future, including the steady state load.

Morgenstern and Gordon (2006) assumed there were no changes in nitrogen export after 1950 (or 1965). Therefore, we used the following equation (called the 'M\&G' model) to replicate their model.

$$
N(t)=N_{0}+\left(N_{1}-N_{0}\right)\left[1-\exp \left(-k\left(t-t_{0}\right)\right)\right]
$$

where $N$ is the nitrogen load (t/yr), $t$ is time (yr), $k(1 / \mathrm{yr})$ is a rate coefficient equal to $1 / M R T, N_{0}$ is the predevelopment load at time $t_{0}$, and $N_{1}$ is the post-development steady state load. $N_{0}, N_{1}$ and $M R T$ vary according to the stream and are taken from Morgenstern and Gordon (2006). Piston flow is reproduced by varying $t_{0}$. Equation 2 was then used to predict the effect of a $48 \%$ reduction in load at $t_{\mathrm{c}}=2015$.

$$
N(t)=N_{C}+\left(N_{2}-N_{C}\right)\left[1-\exp \left(-k\left(t-t_{C}\right)\right)\right]
$$

where $N_{\mathrm{C}}$ is the load at time $t_{\mathrm{C}}$ (the year when the reduction in exports starts) and $N_{2}$ is the new steady state load for the reduced exports and equals $N_{1}(1-0.48) . N_{\mathrm{C}}$ is calculated from Equation 1 by setting $t=t_{\mathrm{c}}$.

In this way the same model and MRTs as Morgenstern and Gordon (2006) were used to estimate how quickly the stream loads are likely to reduce following land use changes and mitigation measures. By adding the loads from the nine major streams, it was also estimated how quickly the total load to the lake is likely to change-although the exclusion of contributions from other sources like point sources makes this only approximate. These predictions provide an independent comparison with the ROTAN model predictions. In the example of Figure 3, $N_{0}=7 \mathrm{t} / \mathrm{yr}, N_{1}=93 \mathrm{t} / \mathrm{yr}, M R T=61 \mathrm{yr}, t_{0}=1950, N_{2}=48 \mathrm{t} / \mathrm{yr}, t_{\mathrm{C}}=2015$ and $N_{\mathrm{C}}=63$ t/yr.

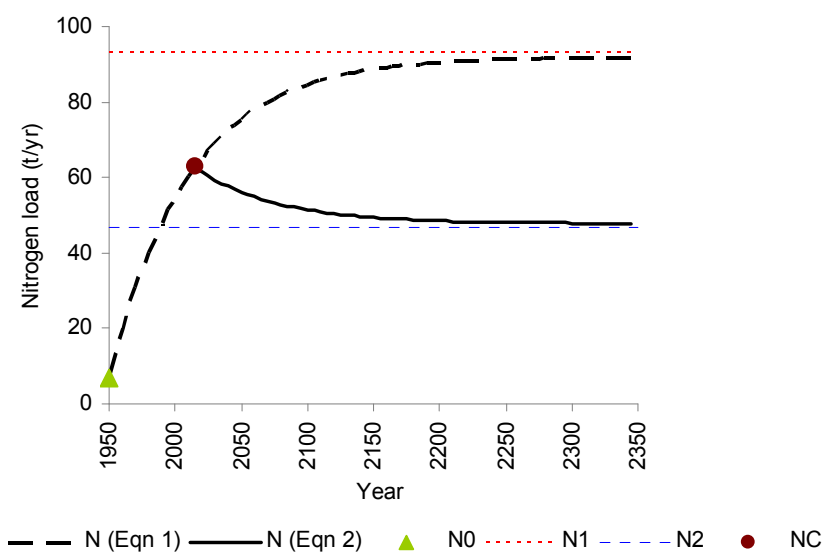

Figure 3. An example of the nitrogen load of a stream as predicted by Equations 1-2 - the M\&G model.

\section{RESULTS}

Figure 4 shows the results predicted by the $M \& G$ model for the equivalent of the ROTAN R- 0 and R-350 scenarios. The nitrogen export reduction for R-350 begins in the year 2015. A good fit is obtained for the stream loads as predicted by Morgenstern and Gordon (2006). Their predicted steady state load is shown for the year 2345 . 
Palliser et al., Using the ROTAN model to predict nitrogen loads to Lake Rotorua, New Zealand
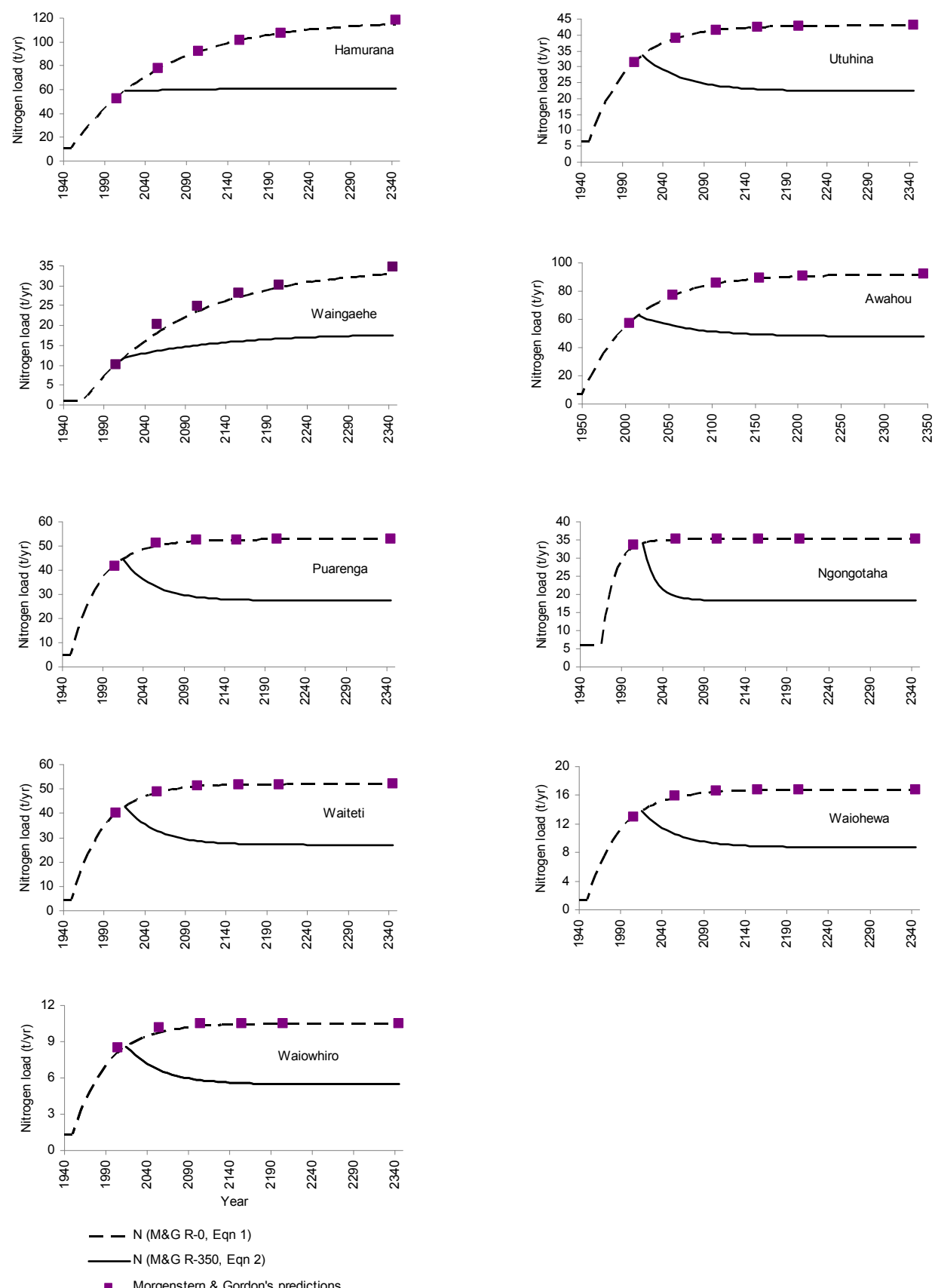

Figure 4. The loads calculated from the $M \& G$ model for each of the nine major streams.

Figure 5a shows the total nitrogen load from the streams for the R-0 and R-350 scenarios as calculated by M\&G along with the R-350 steady state load. Figure 5 b shows the total lake load for scenarios R-0 and R350 along with the R-350 steady state load as predicted by ROTAN. The nitrogen export reduction for R-350 begins in the year 2015 . 

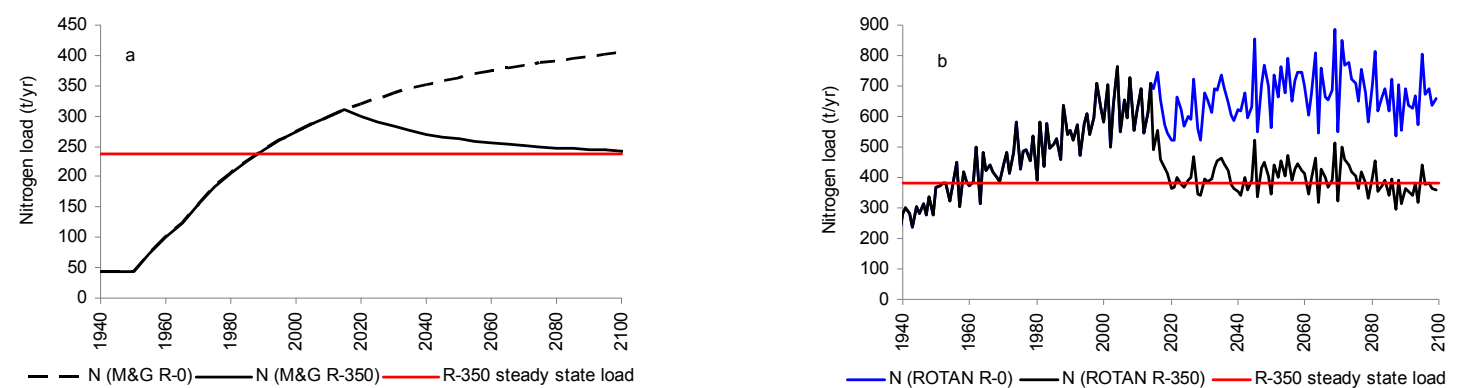

Figure 5. R-0, R-350 and the steady state load for R-350 for: a. The total load from the nine major streams as predicted by the M\&G model. b. The total lake load as predicted by the ROTAN model.

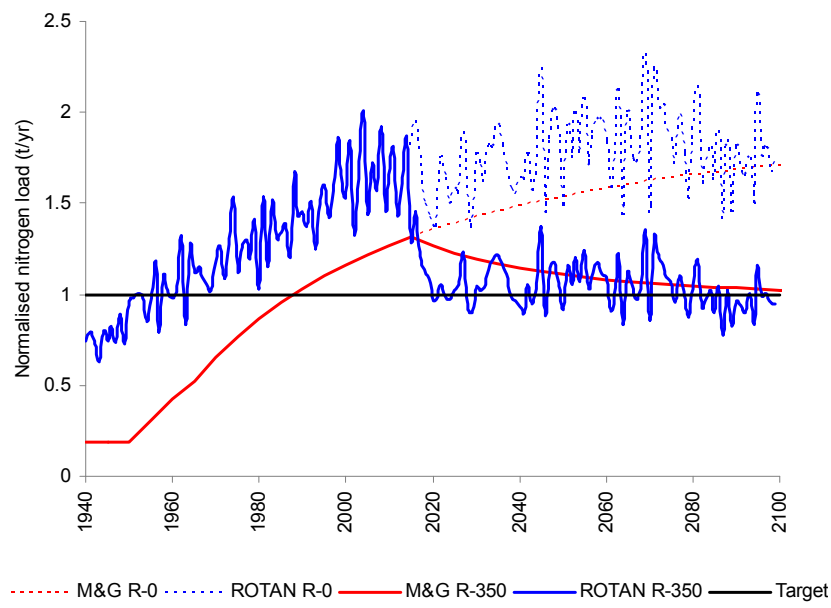

Figure 6. Normalised nitrogen loads for the R-0 and R-350 scenarios: 1) Total from the nine major streams for the R-0 and R-350 scenarios using the M\&G model. 2) Total lake load predicted by ROTAN.

\section{DISCUSSION AND CONCLUSIONS}

Figure $5 \mathrm{a}$ and $\mathrm{b}$ need to be compared to see whether ROTAN and M\&G models predict similar recovery times following a step change in land use and mitigation measures in 2015. However, Figure 5a and b cannot be compared directly because Figure $5 \mathrm{~b}$ includes minor streams, ungauged parts of the catchment, groundwater direct and point sources not all of which were included by Morgenstern and Gordon (2006). In order to compare the loads they have been normalized by the appropriate steady-state load for scenario R-350 (viz., a $48 \%$ reduction from the R-0 scenario load) (Figure 6). For the M\&G and ROTAN models the steadystate loads for scenario R-350 are $237 \mathrm{tN} / \mathrm{yr}$ and $380 \mathrm{tN} / \mathrm{yr}$ respectively.

The M\&G and ROTAN models do not coincide between 1940 and 2010 (Figure 6). The reason is twofoldthe M\&G model assumes a step change in exports in the 1940-50s, whereas ROTAN assumes a more gradual increase in exports over that period; and ROTAN's pre 1940-50s exports are higher than those estimated by M\&G (which are the same as those given in Morgenstern and Gordon (2006)). However, the models have similar normalised loads from 2015 onwards.

The M\&G model predicts a slower response time than ROTAN. High variability in the ROTAN predictions make a comparison difficult. Nevertheless, the ROTAN load drops quickly and is consistently below the M\&G loads during the period 2015-2050. Thereafter, the average ROTAN load and the M\&G load decease at a similar rate.

Both models predict lake loads will be within 5\% of the target by about 2080 (viz., within 65 years). However, whereas the M\&G model suggests that the lake load will be within $10 \%$ of the target by 2060 (viz. 
after 45 years), ROTAN suggests this will be achieved consistently by 2050 (viz., after about 35 years) and possibly earlier.

If the models matched better from 1940-2015 then there would be more confidence in comparing them. It is desirable to re-calibrate the $M \& G$ model using the available data about the changes in land use and nitrogen export prior to 2010. It is conceivable that re-calibration might change the response time predicted by the M\&G model. Although caution is therefore urged about drawing firm conclusions from the comparisons in Figure 6 about lake load response time, it is reassuring that the independent check of ROTAN's recovery time by the M\&G model, gives recovery times not dissimilar to that of the ROTAN model.

\section{ACKNOWLEDGMENTS}

The majority of this work was funded by the Bay of Plenty Regional Council, New Zealand. The remainder of it was funded by Foundation for Research, Science and Technology (FRST) contract C01X0304, New Zealand.

\section{REFERENCES}

Environment Bay of Plenty (EBoP). (2009). Lakes Rotorua \& Rotoiti Action Plan written by Environment Bay of Plenty, Rotorua District Council and Te Arawa Lakes Trust. Environmental Publication 2009/03.

Morgenstern, U., Reeves, R., Daughney, C. Cameron, S., and Gordon, D. (2005). Groundwater age and chemistry, and future nutrient loads for selected Rotorua lakes catchments. GNS Science Report 2004/31. Geological \& Nuclear Sciences, Lower Hutt, New Zealand.

Morgenstern, U. and Gordon, D. (2006). Prediction of future nitrogen loading to Lake Rotorua. GNS Science Consultancy Report 2006/10. Geological \& Nuclear Sciences, Lower Hutt, New Zealand.

Pettersson, A., Arheimer, B., and Johansson, B. (2001). Nitrogen concentrations simulated with HBV-N: new response function and calibration strategy. Nordic Hydrology, 32(3), 227-248.

Rutherford, J.C. (2003). Lake Rotorua nutrient load targets. NIWA Client Report HAM2003-155. Hamilton, New Zealand.

Rutherford, J.C., Tait, A., Palliser, C.C., Wadhwa, S., and Rucinski, D. (2008). Water balance modeling in the Lake Rotorua catchment. NIWA Client Report HAM2008-048. Hamilton, New Zealand.

Rutherford, J.C., Palliser, C.C., and Wadhwa, S. (2009). Nitrogen exports from the Lake Rotorua catchment - calibration of the ROTAN model. NIWA Client Report HAM2009-019. Hamilton, New Zealand.

Rutherford, J.C., Palliser, C.C., and Wadhwa, S. (2011). Prediction of nitrogen loads to Lake Rotorua using the ROTAN model. NIWA Client Report HAM2010-134. Hamilton, New Zealand.

Tamura, T., Yoshida, H., and Hashino, M. (1999). Mathematical modeling for estimating the seasonal changes in streamflow NO3-N concentration. Proceedings IUGG Symposium, Birmingham, July 1999. IAHS Pub., 257, 143-150. 